\title{
Optimization Design and Application of Underground Reinforced Concrete Bifurcation Pipe
}

\author{
Chao Su, ${ }^{1}$ Zhenxue Zhu, ${ }^{1}$ Yangyang Zhang, ${ }^{1}$ and Niantang Jiang ${ }^{2}$ \\ ${ }^{1}$ College of Water Conservancy and Hydropower Engineering, Hohai University, No. 1 Xikang Road, Nanjing 210098, China \\ ${ }^{2}$ Shanghai Investigation, Design \& Research Institute, No. 388 Yixian Road, Shanghai 200434, China \\ Correspondence should be addressed to Yangyang Zhang; zhangyangyang615@163.com
}

Received 18 September 2014; Accepted 12 December 2014

Academic Editor: Chenfeng Li

Copyright (c) 2015 Chao Su et al. This is an open access article distributed under the Creative Commons Attribution License, which permits unrestricted use, distribution, and reproduction in any medium, provided the original work is properly cited.

\begin{abstract}
Underground reinforced concrete bifurcation pipe is an important part of conveyance structure. During construction, the workload of excavation and concrete pouring can be significantly decreased according to optimized pipe structure, and the engineering quality can be improved. This paper presents an optimization mathematical model of underground reinforced concrete bifurcation pipe structure according to real working status of several common pipe structures from real cases. Then, an optimization design system was developed based on Particle Swarm Optimization algorithm. Furthermore, take the bifurcation pipe of one hydropower station as an example: optimization analysis was conducted, and accuracy and stability of the optimization design system were verified successfully.
\end{abstract}

\section{Introduction}

With the development of large hydropower stations especially pumped storage power stations, more and more bifurcation pipes are constructed. In conveyance system of hydropower stations, bifurcation pipe usually locates on the end of pressure pipe and is near the powerhouse, so it undertakes high internal and external water pressure. Bifurcation pipe is a complex space structure and complicated stresses are caused when it suffers from different water conditions. There are many constraints when it is designed, and requirements of hydraulic power and structure are needed to be satisfied; however, there is certain contradiction between these two aspects; they cannot be met mutually. In 1990, Zagars et al. [1] analyzed reinforced concrete bifurcation pipe of Guxu storage power station using structural mechanical method. In 1996, linear and nonlinear finite element methods were used for evaluating stress status of surrounding rock, lining, and reinforcing steel bars of bifurcation pipe under internal and external effect by Lu and Liu [2]. In 2001, Xiao [3] developed the optimization analysis method used for assessing the best structure of large-scale underground reinforced concrete conduit based on failure conditions of reinforced concrete and elastoplastic principle of rock energy dissipation. In 2006, Haixia and Zhefei [4] established an optimization design model of crescent rib branches for steel pipe and developed a corresponding program. In 2009, Ren et al. [5] analyzed stress and deformation of surrounding rock and reinforcement of lining material, stress, and crack in reinforced concrete bifurcation structure of Pushihe pumped storage power station.

In bifurcation pipe design, design safety and reasonable structure based on real structure layout are the main purposes of most designers. Bifurcation pipe optimization can reduce not only structure volume, but also cavern excavation volume [6]. However, most of the current optimization designs are traditional; they only make simple comparisons of some schemes without mathematical programming method and material properties cannot be fully used. A reasonable and efficient method is needed and will be significant for optimization design of bifurcation pipe. 

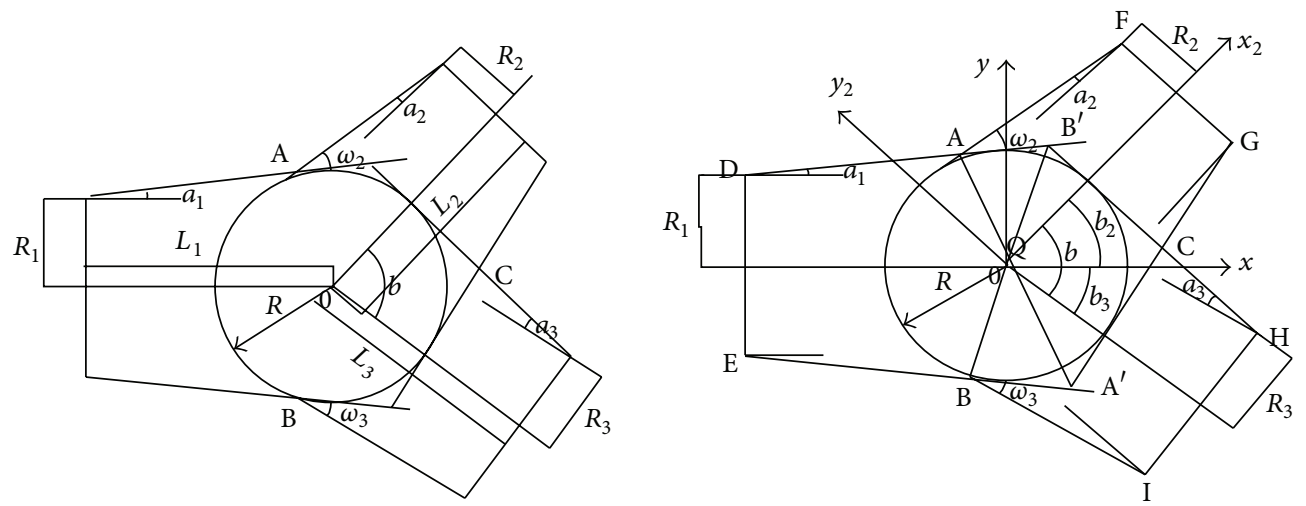

FIGURE 1: Diagrams of Y-type bifurcation pipe and shape-control points.

\section{Parameterized FEM Model and Mesh Program}

Shape-control parameters should be defined according to different bifurcation pipe structures before establishing model, and then the coordinates of shape-control points can be calculated by shape-control parameters. Three-dimensional model containing reinforced concrete blocks of bifurcation pipe is built and an automatic mesh program is developed [79].

Basic design parameters of bifurcation pipe usually are main inlet pipe diameter $R_{1}$, branch pipe outlet diameter $R_{2} R_{3}$, bifurcation angle $b$, joint tangent sphere radius $R$, main half cone angle $a_{1}$, half cone angle of branch cone $a_{2} a_{3}$, waist turning angle $\omega_{2} \omega_{3}$, wall thickness $t_{1} t_{2} t_{3}$ (not shown in Figure 1), and so forth (see Figure 1). Shape-control points and geometric sizes can be calculated according to geometry relations. Shape-control point calculation of bifurcation pipe is done. Calculation of some intermediate variables and auxiliary geometric sizes is necessary [10].

Control point coordinates calculation program was written by Visual Basic. Bifurcation pipe control points and surrounding rock coordinates were input through visualization parameter input interface and data files such as CGFK.TXT, KZD.TXT were exported. According to the defined mesh scheme, the whole three-dimensional finite element mesh was obtained using automatic mesh program CGWG.EXE written by FORTRAN language, converting the mesh data into INP format files of ABAQUS and then the whole mesh can be visualized in ABAQUS [11-13].

\section{Optimization Design Program}

The process of optimization design includes randomization of initial parameters, calculation of structure, judgment of constraints, searching better optimization design scheme, and obtaining the best optimization design results. Implementation usually goes through the following steps: (1) establish a reasonable mathematical model and transform real engineering problems into mathematical problems; (2) solve mathematical problems by certain reasonable and effective optimization method; (3) develop a program using structural analysis method and implement optimization design calculation.

3.1. Mathematical Model. Optimization design in this paper was based on a defined topology structure, so design variables should be chosen according to the topology. Bifurcation pipe shape-control parameters were chosen as design variables. The least concrete volume was set as objective function in order to make full use of reinforced concrete bifurcation pipe material properties.

Constraints contained geometric and strength constraints. Geometric constraints were as follows: (1) half cone angle is $\theta_{1}<a_{i}<\theta_{2}$ and (2) bifurcation angle is $\theta_{3}<b<\theta_{4}$; (3) the shortest bus bar of pipes was no less than $300 \mathrm{~mm}$; and (4) wall thickness of concrete bifurcation pip is $d_{1}<$ $t_{i}<d_{2}\left(\theta_{1}, \theta_{2}\right.$ were the range of half cone angle. $\theta_{3}, \theta_{4}$ were the range of bifurcation angle. $d_{1}, d_{2}$ were the range of wall thickness). Stress constraints included the requirements that tensile stress should be lower than concrete ultimate tensile strength design value and compressive stress should be lower than concrete ultimate compressive strength design value.

3.2. Optimization Design Algorithm. Mathematical model of bifurcation pipe optimization is often nonlinear programming problems. Applicable optimization algorithm includes generalized reduced gradient method, complex method, Particle Swarm Optimization, penalty method, sequential linear programming, and sequential quadratic programming. Particle Swarm Optimization algorithm is adopted in this paper. Particle Swarm Optimization has the advantages of parallel processing, good stability, and the most probability of finding global optimal solution [14].

A group of random particles was firstly initialized in PSO algorithm and particle's searching following optimal particle was conducted in the solution space. In searching process, every particle updated its position and velocity according to the current optimal particle position. The global optimal solution was obtained by continuous iteration and searching [15].

The optimization process of $N$ particles group in $D$ dimension searching space was taken as an example to 
describe the process of optimization algorithms. The state of particle $i$ in time $t$ was set as follows:

$$
\begin{aligned}
& \text { velocity: } V_{i}^{k}=\left(v_{i 1}^{k}, v_{i 2}^{k}, \ldots, v_{i j}^{k}, \ldots, v_{i D}^{k}\right) \\
& \text { position: } X_{i}^{k}=\left(x_{i 1}^{k}, x_{i 2}^{k}, \ldots, x_{i j}^{k}, \ldots, x_{i D}^{k}\right) \\
& \text { personal best position: pbest } X_{i}^{k}=\left(\text { pbest } x_{i 1}^{k}\right. \text {, } \\
& \text { pbest } \left.x_{i 2}^{k}, \ldots, \text { pbest }_{i j}^{k}, \ldots, \text { pbest }_{i D}^{k}\right) \\
& \text { global best position: gbest } X_{i}^{k}=\left(\text { gbest }_{i 1}^{k}\right. \text {, } \\
& \text { gbest } \left._{i 2}^{k}, \ldots, \text { gbest }_{i j}^{k}, \ldots, \text { gbest }_{D}^{k}\right) \text {, }
\end{aligned}
$$

where $i=1,2, \ldots, N ; j=1,2, \ldots, D ; k=1,2, \ldots$, it max; it max is the maximum number of iterations, $i$ represents the $i$ th particle, $j$ represents velocity or the $j$ th dimension, and $k$ represents the count of iterations.

In every iteration process, how to update the position of particle is the key factor affecting optimization algorithm effectiveness. Every particle updates its position according to two optimal solutions (global best position gbest and personal best position pbest). Updated velocity and new position can be defined by following formula:

$$
\begin{gathered}
v_{i j}^{k+1}=v_{i j}^{k}+c_{1} * r_{1}\left(\text { pbest } x_{i j}^{k}-x_{i j}^{k}\right) \\
+c_{2} * r_{2} *\left(\text { gbest } x_{j}^{k}-x_{i j}^{k}\right), \\
x_{i j}^{k+1}=x_{i j}^{k}+v_{i j}^{k+1} .
\end{gathered}
$$

In order to coordinate the global and local optimization capability of PSO algorithm, inertia weight coefficient $\omega$ is set to determine the amount of current velocity particles inherit. Transform the velocity equation to formula (2) and keep the position updating equation:

$$
\begin{aligned}
v_{i j}^{k+1}= & \omega_{k} v_{i j}^{k}+c_{1} * r_{1}\left(\text { pbest }_{i j}^{k}-x_{i j}^{k}\right) \\
& +c_{2} * r_{2} *\left(\text { gbest }_{j}^{k}-x_{i j}^{k}\right) .
\end{aligned}
$$

In the equation, $v_{i j}^{k}$ and $x_{i j}^{k}$ are the $j$ th dimension velocity and position of particle $i$ in the $k$ th iteration respectively. $c_{1}$ and $c_{2}$ are constant, usually $c_{1} c_{2} \in[0,4] ; r_{1}$ and $r_{2}$ are random number between 0 and 1 ; pbest $x_{i j}^{k}$ is the personal best position of particle $P_{i}$ in the $j$ th dimension; gbest $x_{i j}^{k}$ is the global best position of the group.

Linear decreasing inertia weight is usually adopted in PSO iteration calculation process at present. It can accelerate the convergence of iterative calculation and get global best solution quickly. Y. Shi has suggested that inertia weight $\omega$ decreases linearly from 0.9 to 0.4 for better algorithm performance. The linear decreasing formula is as follows:

$$
\omega_{k}=\omega_{\max }-\frac{\omega_{\max }-\omega_{\min }}{\text { it } \max } * k .
$$

The position updating can be described as in Figure 2.

Reinitialization is carried out on particles which is out of range or do not satisfy constraints during development of the program. To ensure the minimum objective function value,

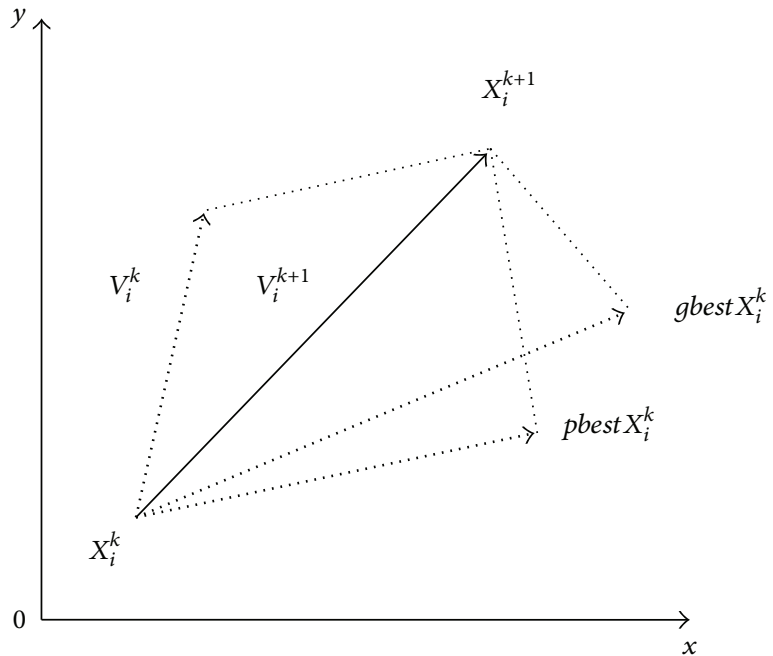

FIGURE 2: Particle updating schematic diagram.

convergence criterion is that the difference between global optimal solutions of last generation and next generation should be less than calculation tolerance $\delta$. At the same time, to avoid too many iterations, the maximum count of iteration is 1000 in program.

3.3. Structural Analysis Method Selection. FEM was used in structure optimization design and calculation in this paper $[16,17]$. FEM is not only with complete and reliable theoretical basis, but also with simple and standardized basis. It can meet the accuracy requirements of engineering calculation and its convergence can be guaranteed. Calculating results can show real structure stress and deformation characteristics.

\section{Engineering Applications}

4.1. Project Overview. A hydropower station with total installed capacity of $1200 \mathrm{MW}$, unit capacity of $300 \mathrm{MW}$ has four units. The depth of \#1 bifurcated pipe is approximately $414 \mathrm{~m}-418 \mathrm{~m}$ and $\# 2$ is approximately $415 \mathrm{~m}$. The impact of complex geological conditions can be considered in the finite element method for structural calculation.

C30 concrete is used for lining in bifurcation pipes construction. Lining thickness is $0.5 \mathrm{~m} \leqslant t \leqslant 1 \mathrm{~m}$. Two $\Phi 20 \mathrm{~mm}$ hoop reinforcement scheme is adopted to prevent concrete cracking under high water pressure during operation period. The main mechanical properties of C30 concrete and steel are shown in Table 1.

The optimization design calculation in this paper focused on normal operation cases. The influence of gravity of rock was considered and it was assumed that all gaps between bifurcation pipe and rock were ignored. Linear calculation was implemented for bifurcation pipe under internal water head around $520 \mathrm{~m}$ (including water hammer pressure) and gravity of surrounding rock without consideration of external water pressure. Finally, structural stress and strain were analyzed. 


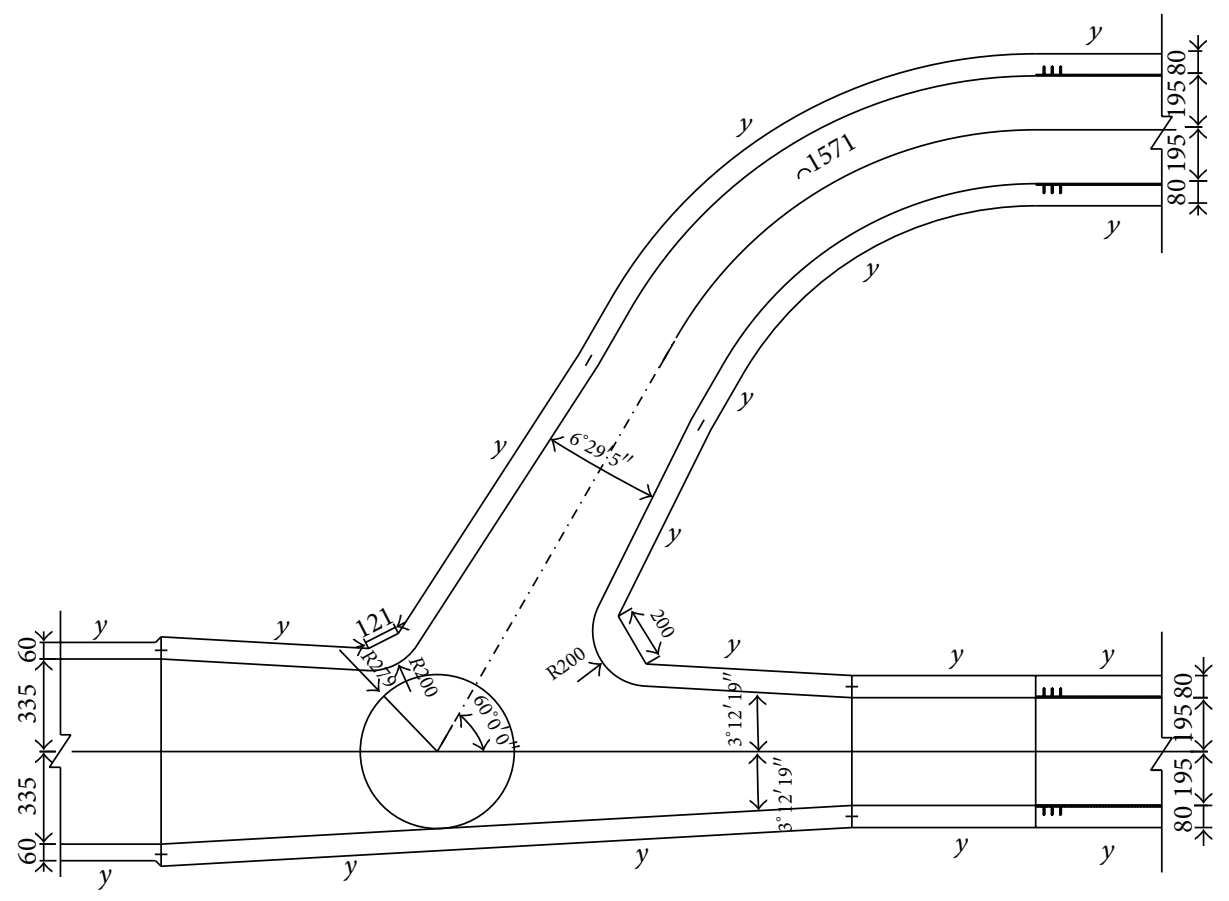

FIGURE 3: Plane design drawing of bifurcation pipe.

TABLE 1: Main mechanical properties of C30 concrete and rebar.

\begin{tabular}{lcc}
\hline Mechanical index & C30 concrete & Rebar \\
\hline Density & $2.5 \mathrm{~g} / \mathrm{cm}^{3}$ & - \\
Elastic modulus $E_{0}$ & $28 \mathrm{GPa}$ & $210 \mathrm{GPa}$ \\
Poisson's ratio $\mu$ & 0.167 & 0.3 \\
Tensile strength & $1.5 \mathrm{MPa}$ & $210 \mathrm{MPa}$ \\
Compressive strength & $15 \mathrm{MPa}$ & $210 \mathrm{MPa}$ \\
\hline
\end{tabular}

4.2. Mathematical Model of Bifurcation Pipe. According to the initial design scheme, parameters of bifurcation pipe size model were confirmed. Structure type is shown in Figure 3. Parameters which can be used as optimization design parameters are half angle of main cone and branch cone $a_{1} a_{2}$, bifurcation angle $b$, main cone wall thickness $t_{1}$, and branch cone wall thickness $t_{2} t_{3}$ (see Figure 4).

Bifurcation pipe concrete volume was set as objective function. According to bifurcation pipe design codes, the range of design variables is shown in Table 2.

$\mathrm{C} 30$ concrete lining is used in this project, so stress control standards in this optimization design are C30 concrete ultimate tensile strength and compressive strength. However, because of reinforcement, tensile stress control standards were calculated using equivalent stress method [18]. According to the amount of bifurcation pipe reinforcement, corresponding design value of ultimate concrete tensile stress can be increased to $7 \mathrm{MPa}$. Considering that reinforcement is mainly subject to tensile stress and its contribution to compressive resistance could be ignored, the corresponding concrete ultimate compressive stress is unchanged. Under
TABLE 2: Value range of design variables.

\begin{tabular}{lc}
\hline Optimization variables & Range \\
\hline Bifurcation angle $b$ & $50 \sim 70^{\circ}$ \\
Half angle of main cone $a_{1}$ & $2 \sim 5^{\circ}$ \\
Half angle of branch cone $a_{2}$ & $2 \sim 5^{\circ}$ \\
Main cone wall thickness $t_{1}$ & $0.5 \sim 1 \mathrm{~m}$ \\
Branch cone wall thickness $t_{2}$ & $0.5 \sim 1 \mathrm{~m}$ \\
Branch cone wall thickness $t_{3}$ & $0.5 \sim 1 \mathrm{~m}$ \\
\hline
\end{tabular}

these stress constraints, bifurcation pipe size should meet the specification requirements by traditional calculating method. Bifurcation pipe optimization design implementation flow is shown in Figure 5.

4.3. Optimization Results Analysis. Bifurcation pipe of a hydropower station was analyzed using the optimization design system and the better design parameters were obtained in Table 3 after 178 iterations. Bifurcation angle is significantly reduced, walls are much thinner, and the amount of concrete is also reduced. The amount of concrete is $2677.41 \mathrm{~m}^{3}$ before optimization and it becomes $1833.30 \mathrm{~m}^{3}$ after optimization, so the amount of concrete reduces to 43.2\% after shape optimization. Reinforcement checking calculation was conducted by using design parameters after optimization.

4.3.1. Surrounding Rock. The distribution of surrounding rock stress and strain is similar before and after optimization with some differences in extreme values. After excavation, the whole rock is almost in compressive status, only a small range 


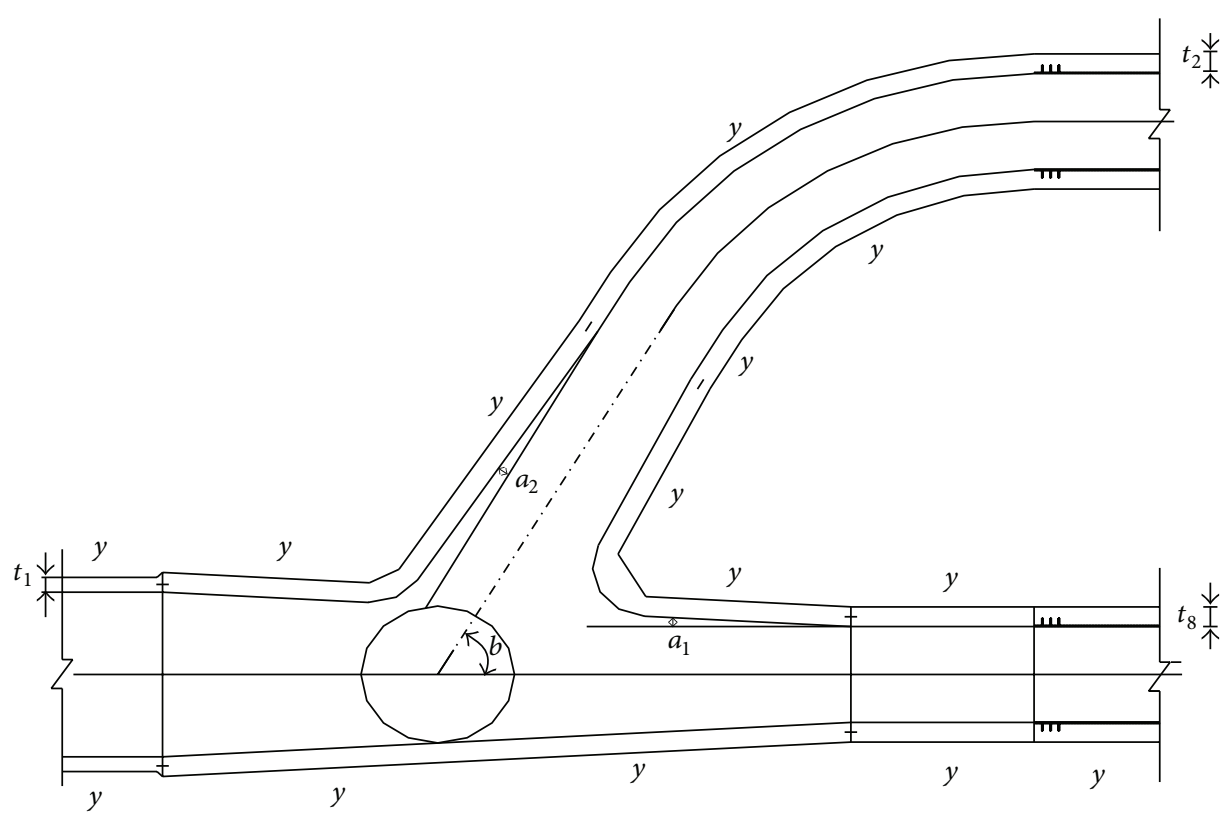

FIGURE 4: Schematic diagram of optimization design parameters.

of tensile status occurs in the bottom of the cavern excavation area at bifurcation area. The maximum tensile stress before and after optimization is $0.48 \mathrm{MPa}$ and $0.59 \mathrm{MPa}$. Compressive stress concentration occurs in the bifurcation area and the maximum compressive stress reaches $-43.71 \mathrm{MPa}$, $-57.56 \mathrm{MPa}$. Large displacement is caused in top and bottom of cavern toward to the cave. Extreme displacement occurs at the top of the bifurcation of the cavern, and displacement before and after optimization is $2.31 \mathrm{~mm}$ and $2.12 \mathrm{~mm}$. After parameters optimization, walls are significantly thinner, cavern excavation volume decreases, and cavern excavation radius is smaller. The top and bottom cavern displacement after excavation has been reduced. Cavern excavation radius has a certain relationship with the surrounding rock displacement.

4.3.2. Bifurcation Pipe. The distribution of bifurcation pipe stress and strain is almost unchanged before and after optimization. Two layers of $\Phi 20 \mathrm{~mm}$ hoop reinforcement were built using T3D2 element in modeling and were inserted into inner side of bifurcation pipe. Analysis of bifurcation pipe with hoop reinforcement is as follows. There is little change in the whole stress distribution. Whole bifurcation stress after inserting hoop reinforcement is significantly reduced. The vast majority of the tensile stress values is $2.0 \mathrm{MPa}$ or less, but there is still stress concentration phenomenon at the bifurcation area and maximum stress here can be eliminated through suitable reinforcement direction arrangement. Extreme displacement is $0.535 \mathrm{~mm}$ at intersecting line in top and bottom of inner surface. All rebars are subject to tensile stress and maximum stress reaches 7.52 MPa (see Figures 6 and 7).

For the inevitable stress concentration in bifurcation and waist areas, some general engineering measures can be taken such as sharp corners rounded, haunch crotch, outsourcing concrete in bifurcation point, configuring hoop,
TABLE 3: Comparison of initial shape and optimization shape.

\begin{tabular}{lcc}
\hline Variable & $\begin{array}{c}\text { Before } \\
\text { optimization }\end{array}$ & $\begin{array}{c}\text { After } \\
\text { optimization }\end{array}$ \\
\hline Bifurcation angle $b\left(^{\circ}\right)$ & 60 & 47.86 \\
Half angle of main cone $a_{1}\left(^{\circ}\right)$ & 3.2 & 4.65 \\
Half angle of branch cone $a_{2}\left({ }^{\circ}\right)$ & 3.2 & 4.57 \\
Main cone wall thickness $t_{1}(\mathrm{~m})$ & 0.6 & 0.57 \\
Branch cone wall thickness $t_{2}(\mathrm{~m})$ & 0.8 & 0.63 \\
Branch cone wall thickness $t_{3}(\mathrm{~m})$ & 0.8 & 0.63 \\
\hline
\end{tabular}

and axial steels. Reducing the external water pressure is also an important measure for stabilizing bifurcation pipe.

\section{Conclusion}

Bifurcation pipe is commonly used in water conveyance system of hydropower station and pumped storage power plant. Its structural safety and stability are directly related to hydropower security and stability, so safety and stability of bifurcation pipe design are very important. Threedimensional FEM parametric reinforced concrete bifurcation pipe program is established in this paper. Particle Swarm Optimization method is selected as the bifurcation pipe structure optimization algorithm and corresponding optimization program is written. FEM calculation is done by calling ABAQUS/Standard module through interface technology between optimization program and ABAQUS to achieve the optimization goals. In the verified project example, the amount of concrete of optimized bifurcation pipe was significantly reduced. At the same time, the comparison of stress and displacement results obtained before and after optimization proved that the program is feasible and stable. 


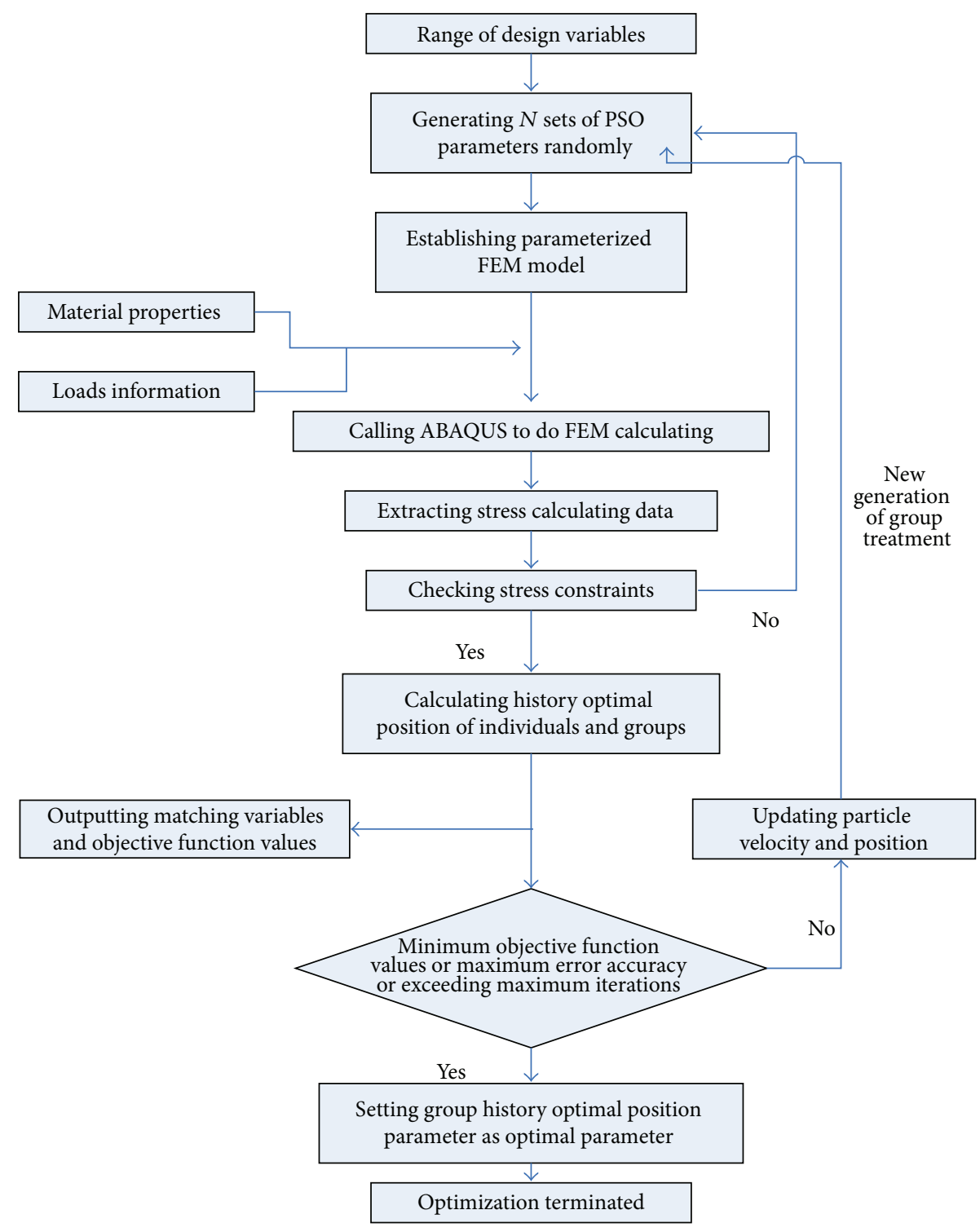

FIgURE 5: Flowchart of optimum design program.

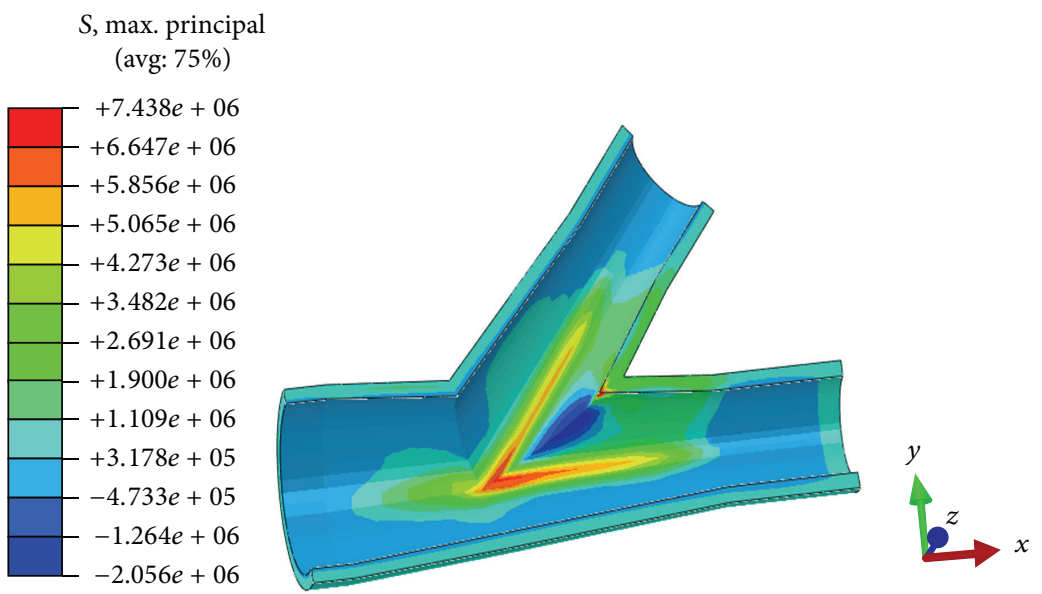

FIgure 6: Principal tensile stress of inside surface. 


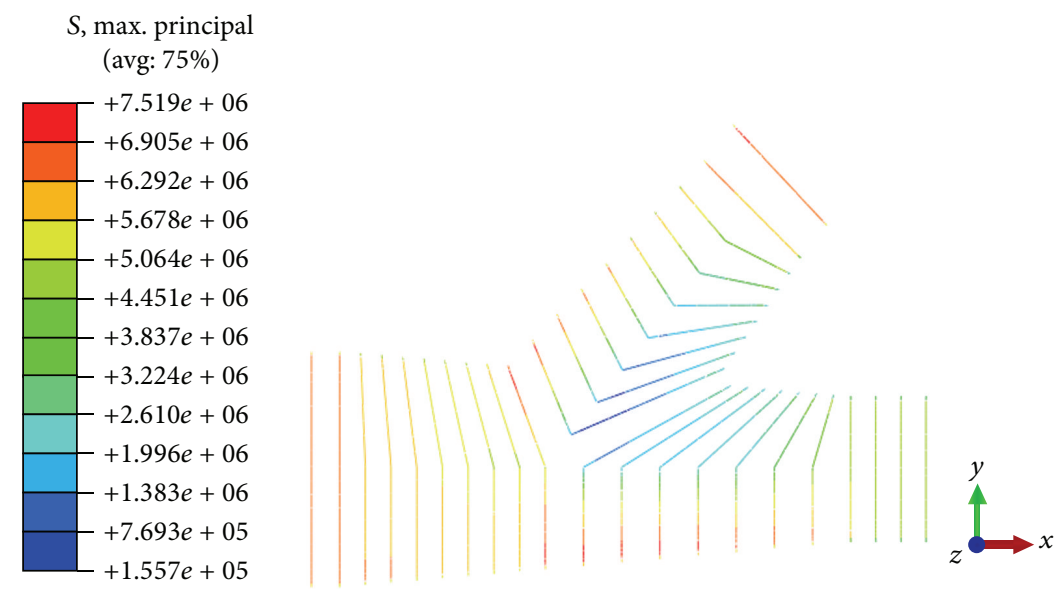

FIGURE 7: Principal tensile stress of hoop rebar.

\section{Conflict of Interests}

The authors declare that there is no conflict of interests regarding the publication of this paper.

\section{Acknowledgments}

The present work is supported by the National Natural Science Foundation of China (no. 51279053) and the Fundamental Research Funds for the Central Universities (no. 2014B36514).

\section{References}

[1] A. Zagars, C. H. Yeh, and H. Lu, "Design of high pressure reinforced concrete bifurcation pipe," Water Power, no. 10, pp. 13-18, 1990.

[2] X. Lu and Q. Liu, "Stress analysis for underground reinforced concrete partition manifold," Journal of Hohai University (Natural Sciences), vol. 9, pp. 24-29, 1996.

[3] M. Xiao, "Optimization analysis of large-scale underground reinforced concrete branching conduit," Journal of Hydraulic Engineering, vol. 32, no. 12, pp. 8-14, 2001.

[4] Y. Haixia and L. Zhefei, "Optimum design of crescent rib branches for steel pipe," Chinese Journal of Solid Mechanics, vol. Z1, pp. 180-180, 2006.

[5] X.-H. Ren, H.-B. Xu, and J.-Q. Shu, "Numerical analysis on surrounding rock and reinforced concrete bifurcation structure of underground tunnels," Journal of Sichuan University (Engineering Science), vol. 41, no. 4, pp. 8-13, 2009.

[6] Q. Liu, Hydropower Plant, China Water Power Press, 2004.

[7] B. Zhang, H. Chen, and L. Zou, "Simple implementation of complex hydraulic structure finite element discretization," Water Resources and Hydropower Engineering, vol. 29, no. 12, pp. 4-6, 1998.

[8] Z. Yufeng and Z. Yiwen, "Review for typical methods of finite element mesh automatic generation and research topics in future," Engineering Journal of Wuhan University, vol. 38, no. 2, pp. 54-59, 2005.

[9] X. Peng and X. Qian, "Zoning-direct method of automatic FE mesh generation," Engineering Mechanics, no. 4, pp. 1396-148, 1993.
[10] W. Hegao, Y. Xingyi, and W. Shougen, "Research and application on system for computer aided design of rib reinforced branch pipe," in Proceedings of the The 6th National Hydropower Penstock Papers, p. 6, 2006.

[11] Z. Bofang, Principles and Applications of Finite Element Method, China WaterPower Press, 1998.

[12] E. Nie and C. Su, "Application of VB and TrueGRID to 3D finite grid automatic mesh generation for lock head," Port \& Waterway Engineering, no. 10, pp. 138-142, 2009.

[13] S. Chao, N. Jiang, and J. Wang, "Optimization design of chamfer triangular gate lock structure," Port \& Waterway Engineering, no. 5, pp. 124-129, 2013.

[14] Q. Feng and Y. Li, "Research on the application of IPSO in engineering optimization problem," Chinese Journal of Scientific Instrument, vol. 26, no. 9, pp. 984-990, 2005.

[15] G. Xu, J.-P. Qu, and Z.-T. Yang, "Improved adaptive particle swarm optimization algorithm," Journal of South China University of Technology (Natural Science), vol. 36, no. 9, pp. 6-10, 2008.

[16] C. Peijiang, B. Tengfeng, and Y. Peng, "3D finite element analysis of underground embedded steel bifurcation pipe," Hydropower Automation and Dam Monitoring, vol. 3, pp. 64-66, 74, 2006.

[17] Q. Yan, "3D finite element analysis of underground embedded steel bifurcation structure," Water Power, vol. 6, pp. 29-32, 2003.

[18] F. Zuoxin and Q. Xiangdong, "Application of finite element method to the design of arch dams," Journal of Hohai University (Natural Sciences), vol. 19, no. 2, pp. 8-15, 1991. 


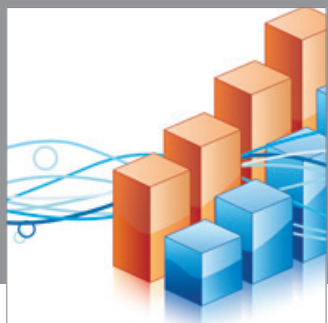

Advances in

Operations Research

mansans

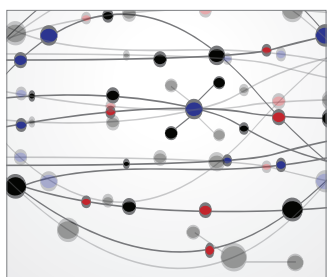

The Scientific World Journal
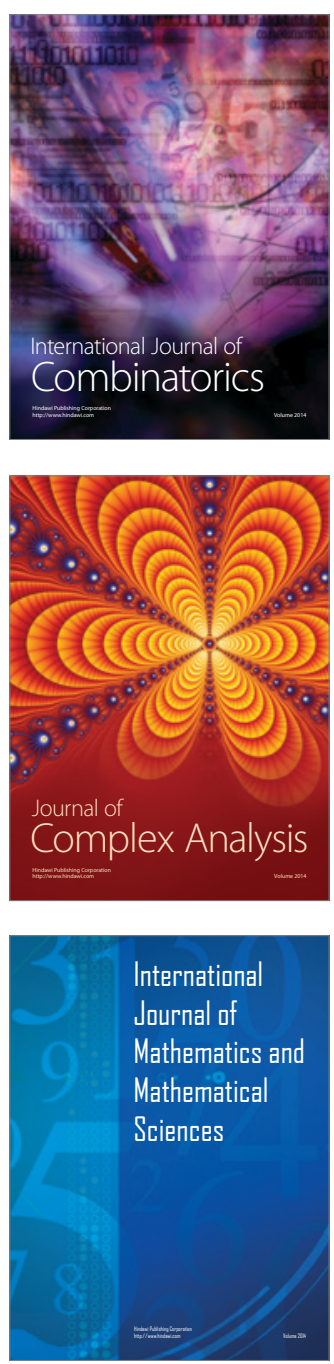
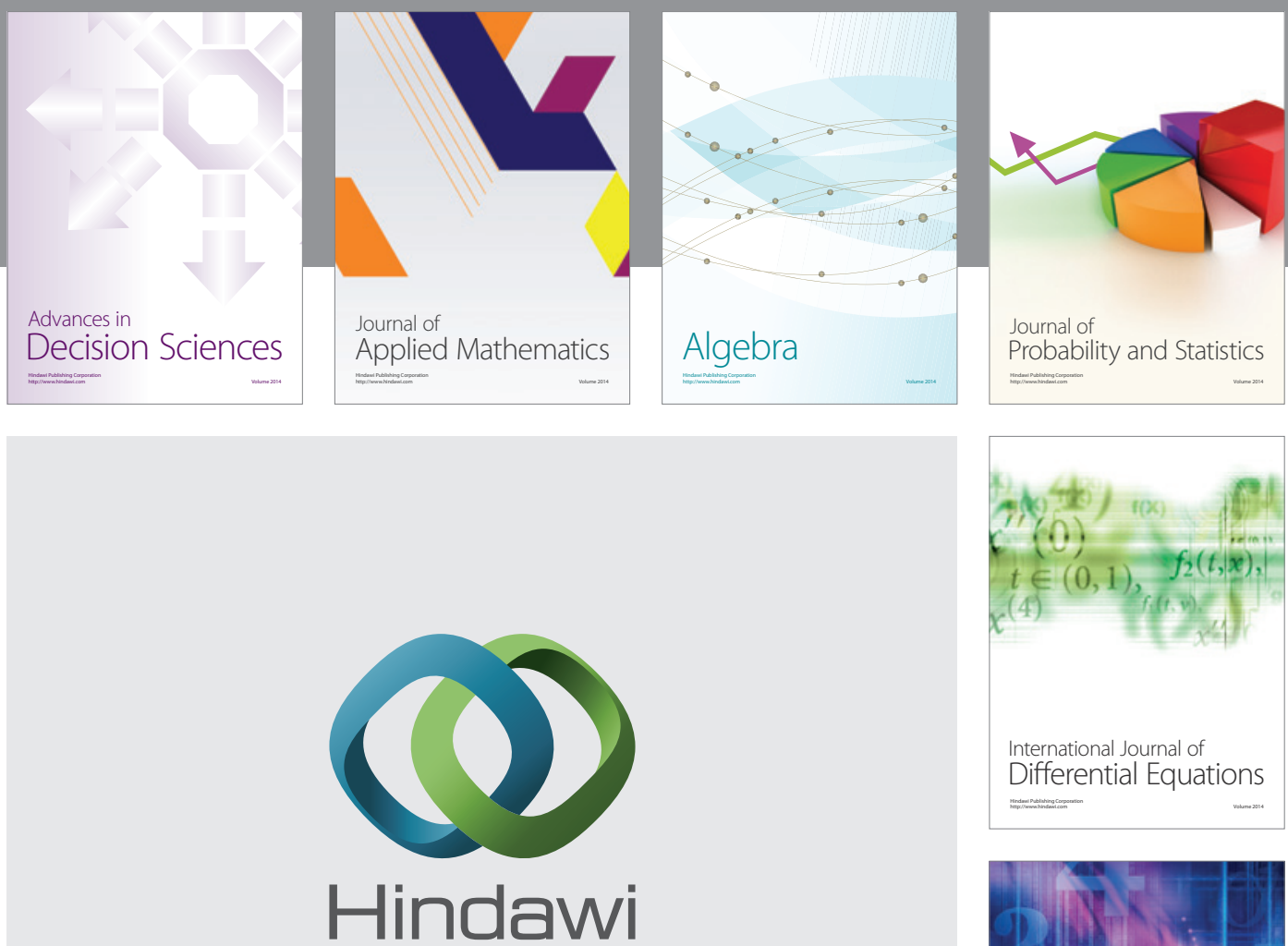

Submit your manuscripts at http://www.hindawi.com
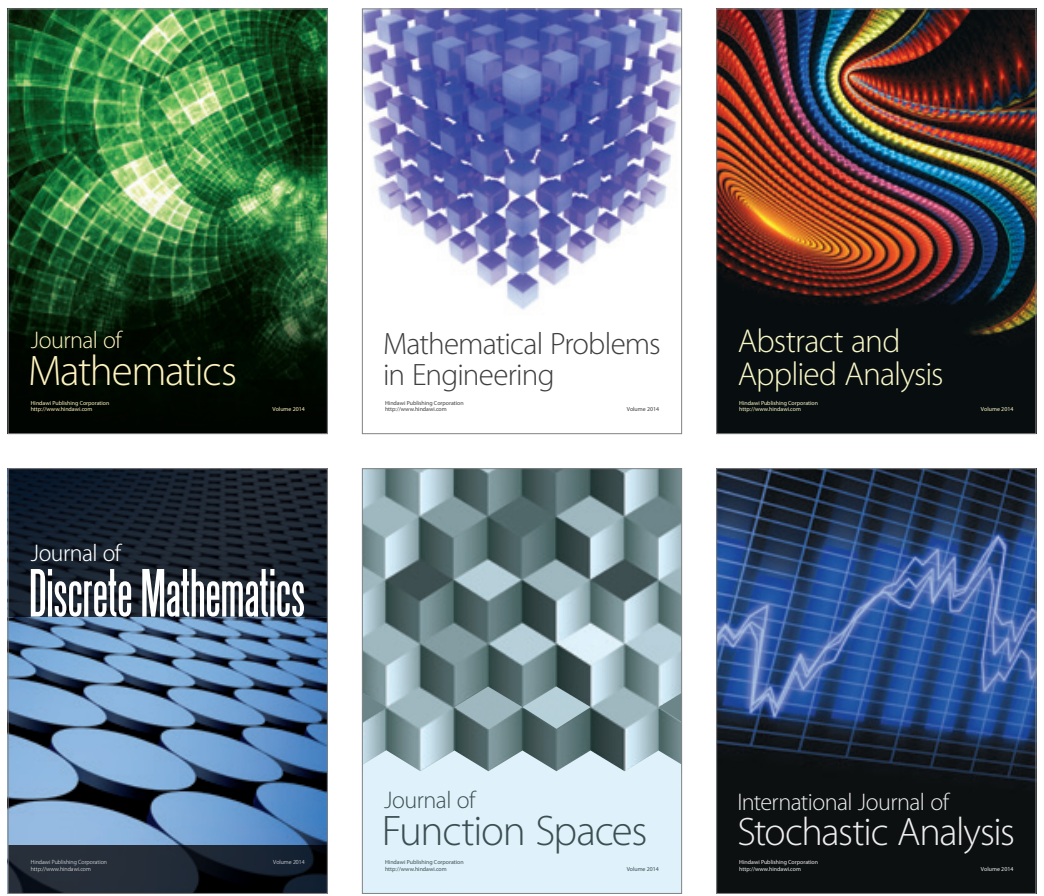

Journal of

Function Spaces

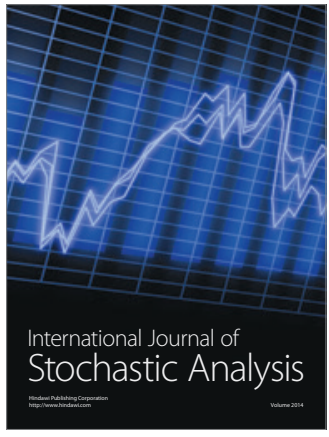

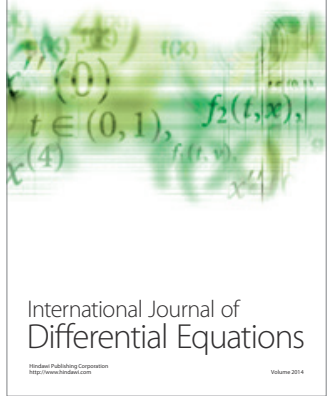
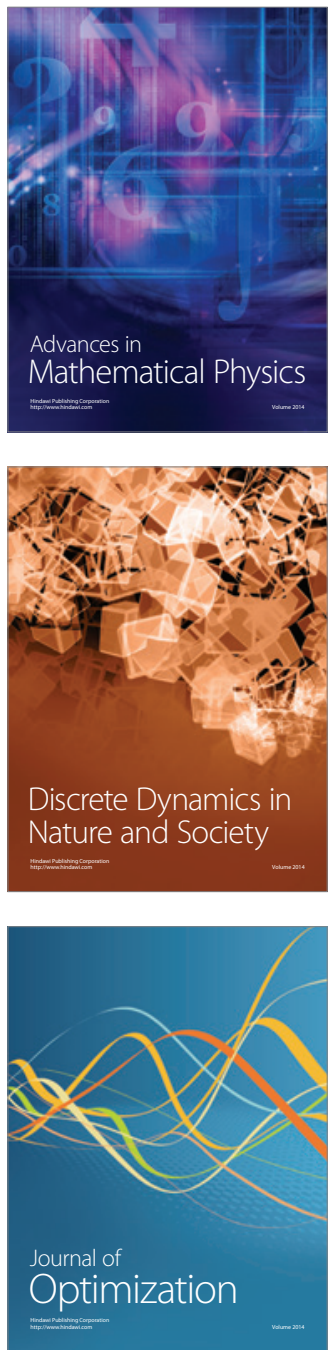